\title{
End of Life Care: Attitudes Toward Autonomy and Legal Instruments
}

\author{
Arthur Oscar Schelp \\ Department of Psychology, Neurology and Psychiatry, \\ Botucatu Medical School, \\ São Paulo State University - UNESP, \\ Brazil
}

\section{Introduction}

The World Health Organization describes healthy life expectancy (World Health Organization, 2011) as a statistic related to life expectancy, which estimates the equivalent years in full health that a person can expect to live based on the current mortality rates in a population. This statement opens up discussion concerning the boundaries between full health and compromise of the same, including the competence of the individual to make their own decisions. Determining the ethical standards for services provided to older individuals with serious illnesses that impair their own understanding of their state, requires an understanding of aspects such as autonomy and the capacity to preserve the best interests of patients and their relatives or guardians.

Respect of a patient's autonomy for decision making, with the preservation of choice, is essential to guarantee an ethical stance in relation to the individual and society. The imposition of "negative" options, which include restriction of movement, the right to drive a vehicle, and other daily activities, and at advanced stages of a disease, injunctions, lead to curtailment and loss. Enhancing the narrow line between restriction of autonomy and legal incapacity is imperative, but the matter is multidimensional, affecting specific patient groups with different civil capacities that have to be taken into consideration. The question is not just medical; it includes many social, cultural, religious, and economic aspects. The medical aspect includes the identification of disturbed competences and the expected duration and grade of incapacity, all confronted with the patient's disease prognosis. Another discussion point is the kind of test or examination that will assure the proper diagnosis of capacity and what is the correct time and form to submit and inform the patient, their relatives and designated curators about the necessity and the risks of nonliability attitudes. The clinical and neuropsychological examination must achieve both the expectations of the elderly patient and their relatives as well as the legal requirements of the eventual injunction. Personnel, who in any form were responsible for the health care of older patients and with impairment decision-making, must be aware that not revealing the prognosis and possible consequences of the loss of ability to make proper and independent choices could make them legally responsible for this attitude. Participation by people involved in supporting patients who are incapacitated or on the way to being incapacitated, 
have an important role to play in designating guardians, curators, and others. The decision to accept proposed treatments in the terminal stages of a disease is another subject for discussion. Some of the advanced directives manifested by older individuals could be outof-date when confronted with new and emerging medical technologies. The society must ensure safeguard measures to avoid the over or sub-interpretation of elderly wishes.

\section{Competency impairment and incapacity in older people}

Elderly patient autonomy can be understood as their capacity to make decisions. Even though the term competency has been used with the same significance as capacity (Dekkers, 2001), some authors prefer to use the term capacity as a broad designation for global ability impairment (Appelbaum, 2007) which could be applied to legal matters the same as to medical questions. It seems to be appropriate and useful to use the expression mental capacity when referring to the ability of someone to make decisions (Mental Capacity Act, 2005). The capacity or incapacity of an individual is an event that comes in parallel with civilization and includes moral, legal, and medical aspects. In the Middle Ages those with incapacities were not submitted to the death penalty, and until now the debate continues on questions like the autonomy of those sentenced (Harrington, 2004). Many authors discuss the capacity to consent to proposed treatments (Roth et al., 1997, Wendler \& Rid, 2011, Karlawish et al., 2005) and nowadays the increasing number of older patients with dementia and other disabilities raise many worries about the autonomy of the ill elderly to decide about their life and others actions related to belongings, etc. (Moye \& Marson, 2007, Defanti et al., 2007, Hughes et al., 2002).

References to end-of-life events are made in the context of the last part of an individual's life span. But when capacity is to be evaluated it could be associated to diseases where the incapacity to make decisions occurs over a short period of time with worsening symptoms affecting not only mental capacity but also motor autonomy with dependence on ventilators for breathing. This situation is associated with the terminal stages of cancer in many organs, and in these cases determination of incapacity is not considered by doctors, proxies, or others. The designation of "intermittent incompetency" proposed by Linda Ganzini (Ganzini et al., 1993), exemplifies the limitations of proposing capacity standards to patients who are burdensome, depressed, and unmotivated. It's clear that not just pathology itself is of consequence, but also the temporality characteristic of the disease, when considering the establishment of elderly incapacity, in the terminal phase of diseases which compromise cognition. The authenticity of decisions, or in other words, the evidence that the choices expressed by the affected person are consistent with his or her values, past history, and decision-making style (Collopy, 1988) must be also taken in account. Considering that the patient's answers are authentic does not mean that the decision-making is completely autonomous (Ganzini \& Lee, 1993).

Individuals with diseases that evolve with dementia represent a particular group, as they will invariably present, during the evolution of the disease, varying levels of incapacity, even considering that there could be periods with some symptom remission or stability. The attempt to stratify patients according to incapacity level conflicts with the distinct evolution of different dementia profiles, which often preserve some competencies, without therefore compromising others, enabling the individual to develop some social functions while unable 
to perform others. In differentiating between Alzheimer's disease/mixed dementia and multi-infarct dementia, the preservation of personality was strongly associated with the latter. Currently, emotional incontinence is associated with multi-infarct dementia, but not mixed dementia (Moroney et al., 1997). The so called sub cortical dementias, like dementia in Parkinson's disease, display visual hallucinations and the impairment of memory and executive functions (Marinus et al., 2003, Galvin et al., 2006), and are associated with patient age and not related to disease duration (Mayeux et al., 1992). The differential cognitive features that distinguish fronto-temporal dementia from Alzheimer's disease include a relative preservation of drawings and calculation performance (Mendez et al., 1996), abilities that could interfere in the interpretation of some structured cognitive tests for determining capacity.

The different attitudes of professionals from different medical specialties towards autonomy (Pioltini et al., 2010), and the family and physician's views of surrogate decision making open a broad discussion about the role of different individuals in decision capacity assessment. The medical professional is more likely to listen to the patient and exchange ideas with colleagues, whereas the family tends toward consensus, assuming a shared position, which may or may not include the patient's wishes (Silberfeld et al., 1996). A systematic review conducted by Wendler (Wendler \& Rid ,2011), found differences in the feelings and attitudes of surrogates on making decisions for other. Apparently, geriatricians and general practitioners have a better knowledge of issues related to maintaining autonomy. This is possibly due to the fact that these professionals have a broader view of the interaction disease/society. In another study, $28 \%$ of general physicians changed their competency diagnosis after a second opinion given by a psychiatrist (Markson et al., 1994), thus enforcing the need for educational programs about the limits and goals of decisionmaking assessment in clinical practice (Ganzini et al., 2003). Even so, doctors are often not prepared to solve problems that involve caregivers. In a study they admitted having little knowledge about support services offered elsewhere and did not see themselves as the answer to most caregiver's problems (Yaffe et al., 2008).

The issue of inter-professional interaction seems to have assumed an increasingly important role regarding the approach towards the independence and capacity of elderly patients in deciding their own interests. In the last decade, numerous publications have emerged that are critical of certain postures and attitudes in bioethics, based on technological values, excessively focused on the physician and that are too reductive (McGrath, 1998). It is evident that all decisions to be taken must respect the free will of the patient (autonomy), with determination of their competence and ensuring confidentiality in dealings with them, their families, and legal representatives. These skills are best assessed if the objectives are based on the assertion that the patients, caregivers and close relatives of the patients should be heard. The ethical commitment that should be observed in the care of patients with possible limitations in understanding their own disease and its likely consequences should be shared with family members, caregivers, and trustees (attorney-in-fact).

It is also interesting to discuss the self-awareness, perceived knowledge, and perceived skills demonstrated by the general population, professionals from different disciplines, and the patient himself, in evaluating impaired capacity in older people. Different studies demonstrate that despite no significant differences have been shown between different 
categories; there is a need for continued educational programs to provide the patient, family and potential caregivers with a better understanding of the course of various diseases. (Schelp et al., 2008, Grey C \& Barton S, 2011, Prince et al., 2007). The acquired knowledge will undergird the actions in end situations that interfere with the ability to express the free will, thereby avoiding false expectations and decreasing psychological distress. The awareness that some diseases could evolve to decisional incapability, enforce the preventive measures that should be taken by the individual and their representatives.

\section{Legal implications of incapacity}

In connection with the ideas of dignity, integrity, and respect for vulnerability of the individuals, the principle of autonomy contributes to the expression of the political morality of the medical and legal systems in modern society (Rendtorff, 2010).

Evidence exists that most individuals with dementia would like to receive information concerning their diagnosis (Karlawish et al. 2005, Marzanski, 2000). On the other hand, the question of when, to whom, and how to communicate information regarding a suspected diagnosis, with all its implications, including loss of the patient's memory of experiences, must take to account several aspects. However, the decision to inform the patient should consider the power of discernment that individual has of their illness. It has been demonstrated that even patients with moderate impairment are not competent to make decisions related to their illness (Karlawish et al., 2005). The decision to remain silent regarding disease prognosis and its implications, including the risk of suicide (Rohde et al., 1995, Maguirre et al., 1996), is justifiable under certain circumstances and should always consider the socio-cultural and religious context in which the patient is inserted. Any medical conduct which could result in physical damage or any kind of personal loss to a citizen should be referred to a judicial sphere and should be a matter for the punishment of those implicated.

The incapacity may be present for delimited social situations and, in many cases, restricted to the family sphere. The requirement of guardianship is a judicial matter and must be decided by a judge after the statement of functional incapacity. Moye (Moye \& Marson, 2007), highlighted two capacity domains which require either cognitive or procedural skills; they are independent living and general financial management. Independent living is a general designation that could be applied in distinct situations. In many cases the elderly still have some dependence on their children and other relatives. They are already retired and take few responsibilities for common social obligations. The situation becomes critical when capacity impairment arrives at the point when the family and surrogates decide to institutionalize the elderly. However specific conditions could be imposed such as prohibiting the person to drive a car (Wild \& Cotrell, 2003), walk alone, swim alone, or cook. All the activities in some way represent the independence to assume and execute individual and collective actions. The thin line between what should be called an independent life and the restriction to perform some actions is related to age, social role, personal values, and family structure. The broad spectrum of incapacitating diseases also plays a role in this evaluation. Recognizing signs of possible impaired financial capacity is another key question to assure independence in daily living activities (Widera et al., 2011). But the apparent loss of the ability to manage economic affairs could be masked by the personal 
limitations of older people to acquire the competency to deal with Internet banking services. Moreover, the normal aging process is almost invariably accompanied by auditory and visual impairment. The assumption that the older a person gets, the less education he or she manages to acquire (Bellak, 1976), is fully applicable to the fast changes and developments in Internet transactions. It will be difficult to guarantee that the individual has impaired judgment to take decisions about their finances, faced with the loss of a particular skill attribute. A decline in some executive functions is a common behavior in many normal aging people.

Even before the institution of the Mental Capacity Act in England in 2005, there was a concern that mental health and incapacity legislation separation could act as a source of discrimination and a limitation in the application of consistent ethical principles across medical law (Dawson \& Szmukler, 2006). The fact that the majority of decisions related to establishing incapacity in the aged occurs outside the judicial sphere (Kapp, 2002), does not imply that the will of the patient will always be accepted, as in certain circumstances the opinion of the family as " natural guardians", or the physician's silent decision could be the appropriate decision (Strong, 1993, Whitney \& McCullough, 2007). As in other contexts, when the decision is based on the values, convictions, and attitudes of the patient, expressed before a diagnosis of incapacity, it must be distinguished from the behaviors in relation to impediments, institution of treatment, and other issues related to that person. Into this scene we have the appearance of community representatives and social workers, further increasing the already complex network of people involved in assessing the capacity of individuals.

After establishing the incapacity state of the elderly individual, with an apparently irreversible prognosis, there are still considerations on the Kantian concept that we should never use people as mere means to other people's ends. Mark Yarborough (Yarborough, 2002), uses this interpretation to discuss using elderly people with dementia in clinical research. The health professional has a fundamental role in suspecting incapacity, nevertheless he also performs a critical and decisive role in finding out the values and beliefs manifested when the individual still had a clear decision-making capacity.

The identification and appointment of a person of reference to receive orientation and patient information is fundamental to preserving the ethics of care for incapacitated elderly individuals. In the absence of a natural partner or legally recognized trustee (administratore di sostegno, tutore - Italian; legal administrator, trustee, guardian and other denominations English), it is up to the professional to identify responsible relatives and potential caregivers, whether they are individuals close to the patient or hired for such work. In a study performed with elderly people, with a mean age of 78 years, there was a low prediction rate between patients, their surrogates, and the physician (Seckler et al., 1991). The process of indicating guardianship to an elderly patient has a better chance of success when the unit social worker makes the recommendation, rather than the physician or a nurse (Burrus et al., 2000). The family's ignorance about substitute indictment (appointment) process; diseases cognition compromise; and absence of a memorandum of the patient wishes, also play a role in this context. We would also like to highlight the finding that most families do not know that physicians tend to use hospital records when coming to their surrogate indictment, allied with direct observation of the patient (Silberfeld et al., 1996). The discrepancies seen in 
attitudes toward the start and development of the surrogate appointment process again shows the need to listen to all the people involved in the care of disabled elderly. The role of health personnel as an information staff is crucial in guaranteeing respect for the patient and preserving the principles manifested by him when healthy and able. In an inquiry presented to medical professionals from different specialties, only the geriatricians spontaneously called attention to the medical and legal aspects of patient injunction, highlighting the need for better disclosure of these aspects (Pioltini et al., 2010). Otherwise it will be no expectations that all older people are competent to take advanced procedure actions or directives to indicate a responsible person to assume decisions in their late moments of life. At this point, it must be assured that the elderly maintains full capacity to express the proper choices. The lack of teaching about what is the role different members of health services have in evaluating incapacity, as well as in how to work with surrogate decisionmakers when taking decisions about handling incapacitated patients, is a highly relevant aspect (White et al., 2010).

\section{The choice of tests to analyze capacity}

The broad spectrum of clinical pictures, evolution duration, associated with relatively maintenance of some abilities, and the precluded notion that there are distinct ways to define what independent life is, together with unspecific means and perceptions of autonomy, opens up discussion as to what should be the appropriate way of evaluating capacity and capacity impairment, including the decision-making autonomy register. In this sense a need arose to establish a structured battery of tests to be applied in several situations where determining capacity is imperative to an individual's welfare.

Integrating the legal perspective of incapacity with clinical knowledge of the issue is essential to safeguard a just intervention process, which does not bring suffering, uncertainty, and moral and financial costs to the patient and his relatives. The use of Mini Mental Score Examination (MMSE); (Folstein \& Folstein, 1975) in evaluating dementia pictures is very widespread. Even so, the great variability in cutoff scores for determining incapacity must be considered. Also, even considering that scores below 16 represent a high probability of an association with incapacity (Etchells et al., 1999); these values are much lower in illiterate patients who also belong to other social groups (Bertolucci et al., 1994 ) which limits the specificity and sensitivity of the test, whose aim is to determine incapacity to make decisions.

Until the beginning of the 90 's, tests in the USA to evaluate the competence to make decisions were based on five categories 1) Evidencing a choice, 2) Reasonable outcome of choice, 3) Choice based on "rational" reasons, 4) Ability to understand, and 5) Actual understanding (Roth et al., 1977). In 1992, Bonnie (Bonnie, 1992) proposed a theoretical reform of competence parameters for criminal defendants, which was later restructured for clinical application by Grisso (Grisso \& Appelbaum, 1995), as the MacArthur Assessment Test. This test analyzes four functional domains: 1) Capacity to communicate a choice; 2) Understand the Relevant Information; 3) Appreciate the situation and its consequences, and 4) Reasons about offered options. Since then, the MacSAC-CD (MacArthur Structured Assessment of the Competencies of Criminal Defendants) has been used to evaluate the capacity of public defendants in criminal trials, and has been well accepted. The MacSAC- 
CD was designed to evaluate two major dimensions, namely adjudication and decisional competence (Cruise \& Rogers, 1998). The authors draw our attention to the limitations of this test when analyzing aspects of malingering attitudes. Even so, Hoge (Hoge et al., 1997), argued that the test had solid foundations both from a legal aspect, and in psycho-legal assessment theory. Agreement rates between mental health professionals and court determinations have been found to exceed 90\% (Freckelton, 1996), which refers to the "fitness" to stand trial. It is still rational to imagine that capacity tests, which can trigger a process of civil injunction, should be interchangeable and indiscriminately applied, both for legal ends, and for guiding daily activities. It is mandatory to avoid both malingering attitudes and pseudo incapacity diagnosis. A philosophical criticism of MacCAT-T (McArthur Competence Assessment Tool-Treatment), which is basically the same test that has been applied to evaluate competency to act in judging the capacity of others, is that the test does not analyze non-cognitive aspects of behavior, or rather emotional, socio-cultural, and other influences (Breden \& Vollman, 2004). Accordingly, multiple tests must be considered which include evaluating emotional factors, including references to cultural, social, and religious values.

\section{Attitudes towards inclusion of older people in research protocols}

Increased research on diseases that affect the elderly and their treatment have added to the ethical aspects, both for their participation in protocols and in decisions regarding the indication and use of high-cost medications. An inquiry in Sweden demonstrated that women and laypersons were generally keener to preserve a patient's integrity and medical professionals were more willing than laypersons to permit individuals with dementia to participate in placebo-controlled trials (Peterson \&Wallin 2003). Confidentiality in research is critically important, but it is not an absolute legal principle in either research or clinical settings (Stiles \& Petrila, 2011). The informed refusal to participate in a research project is also a matter for surrogates of elderly patients with incapacitating diseases (Meisel \& Kuczewski, 1996).

\section{Autonomy of older patients in advanced stages of incapacitating diseases}

One critical aspect to be considered is the location for end-of-life care for elderly incapacitated patients. One study showed that from a family perspective, elderly patients who received home care with hospital services were more likely to report a favorable dying experience (Teno et al., 2004). In this survey, among those suffering dementia, the largest group remained at home with nursing care. Only a small group died at home with hospital care, similar to those who died in hospital. In a questionnaire applied in Japan (Ikezaki \& Ikegami, 2011), there were a relatively high number of dementia and severe cognitively impaired patients with "unknown" place of dying, with or without nursing support. The authors attribute the findings to the fact that life support treatment preferences of family members in Japan were ignored by most of the general public the same as for the bereaved of patients who died in hospital (Ikegami \& Ikezaki, 2010). The results of those epidemiological evaluations exemplifies the fact that in some cultures, including Japan, some diseases, particularly when severe cognitive impairment is present, receives distinct attention in their late moments of life. There seems to be consensus that shared decisions have advantages when they refer to end-of-life care for terminally ill patients (Sittisombut et 
al., 2009; Lee JCY et al., 2003). The need to encourage this to happen not only regarding the place of death, but also the form of care, requires debate and should be looked at by health authorities.

There are no valid protocols or agreed norms for suspending medication or interrupting other support measures, (Parson et al., 2010, and Derse, 1999), confirming the difficulty in establishing standards. Medical professionals have not demonstrated a clear consensus on palliative measure to be used, including posture in relation to family and trustees (Schneiderman et al., 1993; Hinkka H et al., 2002; Richter J et al., 2001, and Eisemann M et al., 1999).

Another aspect, which can be embarrassing, is the notion that the cost factor (burden) influences the society's attitudes toward patient autonomy in end-of-life decision-making (Kwon et al., 2009). The authors highlight this "anxiety" and suggest an open and balanced discussion on burden with the family, with possible adequate welfare support. The actual patients themselves give the impression, when they are competent, that the family's values in relation to costs must be taken into account when dealing with end-of-life decisions (Doukas \& Gorenflo 1993). The discussion about the burden with surrogates and the family must take into account the wishes and beliefs manifested by the patient when they were in full charge of their decision making capacity.

The start of palliative care with the suspension of ineffective and unnecessary care for elderly and incapacitated patients in the terminal and irreversible stage of the life is also recognized as orthothasia in Brazil and some other countries (Pinto, 1991; Asorta-Bilajac\& Segota, 2010; Gutiérrez-Samperio, 2001). To guarantee comfort, respect, and autonomy in line with the wishes of patients in the end stage of life is the ethical obligation of health professionals. However the circumstances in which such measures will be applied, as well as the factors which determine the place, manner, and the diligence applied to the process, are complex and must be the combined opinions of the actual patient and their family and legal representatives.

The upward trend in life expectancy increases the chances that more elderly patients will attend intensive care units and receive breathing support and feeding assistance. To handle this situation, many professionals have assumed the assurance behavior, imposing additional unnecessary services. In most cases, a defensive stance is practiced based on the belief that the procedures are medically acceptable by professional expert panels, but the attitudes assumed by physicians are in many circumstances aimed at avoiding malpractice claims (U.S. Office Technology Assessment, 1994).

The decision to not resuscitate a terminally ill patient is generally limited to the health staff, that is, the nurse and the physician, with compliance from surrogates to medical recommendations (Eliasson et al., 1997). The option to start or withhold tube feeding or gastrostomy is controversial and includes the physician's perception of patient and family wishes and liability concerns (Bell et al., 2008). For some authors the evidence that dysphagia is always a terminal symptom in dementia rules out the recommendation to use gastrostomy (Regnad et al., 2010). It must be remembered, to consider the offering of taste pleasure or feeding sensation to older people with tube feeding or gastrostomy. The use of positive airway pressure machines (CPAP), to guarantee ventilatory support for incapacitate 
patients at the end phase of life instead of more sophisticated apparatus with volumetric control, is preferable.

Finally it is important to stress that determining incapacity with autonomy restriction for the patient is a step-by-step process, with moment-to-moment characteristics and should be implemented in accordance with the circumstances in which the diagnosis of incapacity is requested. It would be naïve to imagine that uniform protocols or norms could be established for application in all situations. Analysis must me multidisciplinary with flexible individualized instruments. Establishment of a legal injunction must take into consideration the clinical diagnosis of incapacity as well as the advance directives expressed by the patient, a matter that is receiving little attention from responsible authorities in many countries. Nevertheless, people can find support of non-governmental organizations, receiving information, guidance, and preparation to stressful moments in final stages of life (Burrel, 2008 ). In many situations, there are more concern with informed consent for treatment and procedures to be adopted than to the advance directives expressed by the patient in any form at prior to manifestations of incapacity.

Birth and death are two critical transitions in a life time. When a child is born, it receives a legal identification that ensures rights which must be guaranteed by parents, its family, and the rest of the society to which he or she belongs. On the other side, with the approach of death of older people, it should be assured that the moral and legal obligation to the values and beliefs of the elderly will be respected and applied. The decision to request relatives to take actions which guarantee the patient complete respect of his or her expressed wishes up to or before the onset of the state of incapacity is never related to the diagnosis or proposed therapeutic measures, but to an attitude towards maintaining the autonomy of old people in their final stage of life. The patient's wishes must be an obligation for descendants and guardians, not just a moral one but a legal one which must be taken in account by health personnel when dealing with older patients in their final moments of life.

\section{References}

Appelbaum, P.S. (2007). Assessment of Patient's Competence to Consent to Treatment. New England Journal of Medicine, Vol.357, No.18, (November 2007), pp. 1834-1840, ISSN 0028-4793

Asorta-Bilajac, I. \& Segota, I. (2010). Is there a Death with Dignity in Today's Medicine? International Journal of Bioethics, Vol.21, No.4, (December 2010), pp. 149-156, ISSN 1145-0762

Bell, C., Somogyi-Zalud, E., Masaki, K., Fortaleza-Dawson, T. \& Blanchette, P.L. (2008). Factors Associated with Physician Decision-Making in Starting Tube Feeding. Journal of Palliative Medicine, Vol.11, No. 6, (July 2008), pp.915-924, ISSN 1096-6218

Bellak, L. (1976). Psychological Aspects of Normal Aging, In: Geriatric Psychiatry, L. Bellack \& B.K. Toksoz, (Eds.), 21, Grune \& Stratton, ISBN 0808909673, New York.

Bertolucci, P.H.F., Brucki, S.M.D., Campacci, S.R. \& Juliano, Y. (1994). The Mini Mental Examination: Impact of Escolarity. Arquivos de Neuropsiquiatria, Vol.52, No.1, (March 1994), pp. 1-7, ISSN 0004-282X

Bonnie, R.J. (1992). The Competence of Criminal Defendants: a Theoretical Reformulation. Behavioral Sciences and the Law, Vol.10, No.3, (Summer 1992), pp. 291-316, ISSN 1099-0798 
Breden, T.M. \& Vollman, J. (2004). The Cognitive Based Approach of Capacity Assessment in Psychiatry: a Philosophical Critique of the MacCAT-T. Health Care Analysis, Vol.12, No.4, (December 2004), pp. 273-283, ISSN 1065-3058

Burrel, G.M. (2008). Websites and addresses page of organizations, In: Freedom to Choose: How to make End-of-Life Decision on your Own Terms, D.A. Lund (Ed.), 125, Baymond Publishing Company Inc., ISBN 978.0.89503-340-6, Amityville, New York

Burrus, J.W., Kunik, M.E., Molinari, V., Orengo, C.A. \& Rezabek, P. (2000). Guardianship Applications for Elderly Patients: Why Do They Fail? Psychiatrics Services, Vol.51, No.4, (April 2000), pp. 522-524, ISSN 1075-2730

Collopy, B.J. (1988). Autonomy in Long Term Care: Some Crucial Distinctions. The Gerontologist, Vol.28, Suppl., (June 1997), pp. 10-17, ISSN 0016-9013

Cruise, K.R. \& Rogers, R. (1998). An Analysis of Competency to Stand Trial: an Integration of Case Law and Clinical Knowledge. Behavioral Sciences and the Law, Vol.16, No.1, (Winter 1998), pp. 35-50, ISSN 1099-0798

Dawson, J. \& Szmukler, G. (2006). Fusion of Mental Health and Incapacity Legislation. The British Journal of Psychiatry, Vol.188, (June 2006), pp. 504-509, ISSN 0007-1250

Defanti, C.A., Tiezzi, A., Gasparini, M., Gasperini, M., Congedo, M., Tiraboschi, P., Tarquini, D., Pucci, E., Porteri, C., Bonito, V., Sacco, L., Stefanini, S., Borghi, L., Colombi, L., Marcello, N., Zanetti, O., Causarano, R., Primavera, A. \& Bioethics and Palliative Care in Neurology Study Group of the Italian Society of Neurology. (2007). Ethical Questions in the Treatment of Subjects with Dementia. Part I. Respecting Autonomy: Awareness, Competence, and Behavioral Disorders. Neurological Sciences, Vol.28, No.4, (August 2007), pp. 216-231, ISSN 1590-1874

Dekkers, W.J.M. (2001). Autonomy and Dependence: Chronic Physical Illness and DecisionMaking Capacity. Medicine, Health Care, and Philosophy, Vol.4, No.2, (2001), pp. 185192, ISSN 1386-7423

Derse, A.R. (1999). Making-Decision About Life-Sustaining Medical Treatment in Patients with Dementia. The Problem of Patient Decision-Making Capacity. Theoretical Medicine and Bioethics, Vol.20, No.1, (January 1999), pp. 55-67, ISSN 1386-7415

Doukas, D.J. \& Gorenflo, W. (1993). Analyzing the Values History: An Evaluation of Patient Medical Values and Advance Directives. The Journal of Clinical Ethics, Vol.4, No.1, (Spring 1993), pp. 41-45, ISSN 1046-7890

Eisemann, M., Richter, J., Bauer, B., Bonelli, R.M. \& Porzsolt, F. (1999). Phicisian's DecisionMaking in Incompetent Elderly Patients: a Comparative Study between Austria, Germany (East,West), and Sweden. International Psychogeriatrics, Vol.11, No.3, (September 1999), pp. 313-324, ISSN 1041-6102

Elliasson, A.H., Howard, R.S., Torrington, K.G., Dillard, T.A. \& Phillips, Y.Y. (1997). Do-notResuscitate Decisions in the Medical ICU: Comparing Physician and Nurse Opinions. Chest, Vol.111, No.4, (April 1997), pp. 1106-1111, ISSN 0012-3692

Etchells, E., Darzins, P., Siberfeld, M., Singer, M., McKenny, J., Naglie, G., Katz, M., Guyatt, G.H., Molloy, D.W. \& Strang, D. (1999). Assesment of Patient Capacity to Consent to Treatment. Journal of General Internal Medicine, Vol.14, No.1, (January 1999), pp. 27-34, ISSN 0884-8734

Folstein, M.F. \& Folstein, S.E. (1975). Mini-Mental State a Practical Method for Grading the Cognitive State of Patients for the Clinican. Journal of Psychiatric Research, Vol.12, No.3, (November 1975), pp. 189-198, ISSN 0022-3956 
Freckelton, I. (1996). Racionality and Flexibility in Assesment of Fitness to Stand Trial. International Journal of Law Psychiatry, Vol.19, No.1, (Winter 1996), pp. 39-59, ISSN 0160-2527

Galvin, J.E., Pollack, J. \& Morris, J.C. (2006). Clinical Phenotype of Parkinson Disease Dementia. Neurology, Vol.67, No.7, (November 2006), pp.1605-1611, ISSN 0028-3878

Ganzini, L. \& Lee, M.A. (1993). Authenticity, Autonomy, and Mental Disorders. The Journal of Clinical Ethics, Vol.4, No.1, (Spring 1993), pp. 55-58, ISSN 1046-7890

Ganzini, L., Lee, M.A., Heintz, T. \& Bloom, J.D. (1993). Is the Patient Self-Determination Act Appropriate for Elderly Persons Hospitalized for Depression? The Journal of Clinical Ethics, Vol.4, No.1, (Spring 1993), pp. 46-50, ISSN 1046-7890

Ganzini, L., Volicer, L., Nelson, W. \& Derse A. (2003). Pitfalls in Assessment of DecisionMaking Capacity. Psychosomatics, Vol.44, No.3, (May-June 2003), pp.237-243, ISSN 0033-3182

Grey, C. \& Barton, S. (2011). Severe Self-Neglect: When is Decision-Making Capacity Lost? Journal of the American Geriatrics Society, Vol.59, Suppl.1, (April 2011), pp. S170, ISSN 0002-8614

Grisso, T. \& Appelbaum, P.S. (1995). The MacArthur Treatment Competence Study: III. Abilities of Patients to Consent to Psychiatric and Medical Treatments. Law and Human Behavior, Vol.19, No.2, (April 1995), pp. 127-148, ISSN 0147-7307

Gutierrez-Samperio, C. (2001). Bioethics in the Face of Death. Gaceta Medica de México, Vol.137, No.3, (May-June 2001), pp. 269-276, ISSN 0016-3813.

Harrington, C.L. (2004). Mental Competence and End-of Life Decision Making: Death Row Volunteering and Euthanasia. Journal of Health Politics, Policy and Law, Vol.29, No.6, (December 2004), pp.1109-1151, ISSN 0361-6878

Hinkka, H., Kosunen, E., Lammi, E.K., Metsanoja, R., Puustelli, A. \& Kellokumpu-Lehtinen, P. (2002). Decision Making in Terminal Care: a Survey of Finnish Doctor's Treatment Decisions in End-of-Life Scenarios Involving a Terminal Cancer and a Terminal Dementia Patient. Palliative Medicine, Vol.16, No.3, (May 2002), pp.195203, ISSN 0269-2163

Hoge, S.K., Bonnie, R.J., Poythress, N., Monahan, J., Eisenberg, M. \& Feucht-Haviar, T. (1997). The MacArthur Adjudicative Competence Study: Development and Validation of a Research Instrument. Law and Human Behavior, Vol.21, No.2, (April 1997), pp. 141-179, ISSN 0147-7307

Hughes, J.C., Hope, T., Savulescu, J. \& Ziebland, S. (2002). Carers Ethics and Dementia: a Survey and Review of the Literature. International Journal of Geriatric Psychiatry, Vol.17, No.1, (January 2002), pp. 35-40, ISSN 0885-6230

Ikegami, N. \& Ikezaki, S. (2010). Life Sustaining Treatment at End-of-Life in Japan: Do the Perspectives of the General Public reflect those of the Bereaved of Patients who Have Died in Hospitals? Health Policy, Vol.98, No.2-3, (December 2010), pp. 98-106, ISSN 0168-8510

Ikezaki, S. \& Ikegami, N. (2011). Predictor's of Dying at Home for Patients Receiving Nursing Services in Japan: a Retrospective Study Comparing Cancer and NonCancer Deaths. BioMed Central Palliative Care, Vol.10, (March 2011), pp. 3, ISSN 1472-684X 
Kapp, M.B. (2002). Decisional Capacity in Theory and Practice: Legal Process Versus "Bumbling Through". Aging and Mental Health, Vol.6, No.4, (November 2002), pp. 413-417, ISSN 1360-7863

Karlawish, J.H.T., Casarett, D.J., James, B.D., Xie, S.X. \& Kim, S.Y.H. (2005). The Ability of Persons with Alzheimer Disease (AD) to Make Decision about Taking an AD Treatment. Neurology, Vol.64, No.9, (May 2005), pp. 1514-1519, ISSN 0028-3878

Kwon, Y.C, Shin, D.W., Lee, J.H., Heo, D.S., Hong, Y.S., Kim, S.Y. \& Yun, Y.H. (2009). Impact of Perception of Socio-Economic Burden on Advocacy for Patient Autonomy in End-of-Life Decision-Making: a Study of Societal Attitudes. Palliative Medicine, Vol.23, No.1, (January 2009), pp. 87-94, ISSN 0269-2163

Lee, J.C.Y., Chen, P.P., Yeo, J.K.S. \& So, H.Y. (2003). Hong Kong Chinese Teacher's Attitudes Toward Life-Sustaining Treatment in Dying Patients. Hong Kong Medical Journal, Vol.9, No.3, (June 2003), pp. 186-191, ISSN 1024-2708

Maguirre, C.P., Kirby, M., Coen, R., Coakley, D., Lawlor, B.A. \& O'Neill, D. (1996). Family Member's Attitudes Toward Telling the Patient with Alzheimer's Disease their Diagnosis. British Medical Journal, Vol.313, No.7056 (August 1996), pp.529-530, ISSN 0959-8138

Marinus, J., Visser, M., Verswey, N.A., Verhey, F.R., Middelkoop, H.A., Stiggelbout, A.M. \& van Hilten, J.J. (2003). Assessment of Cognition in Parkinson's Disease. Neurology, Vol.61, No.9, (November 2003), pp. 1222-1228, ISBN 0028-3878

Markson, L.J., Kern, D.C., Annas, G.J. \& Glantz, L.H. (1994). Physician Assessment of Patient Competence. Journal of the American Geriatrics Society, Vol.42, No.10, (October 1994), pp. 1074-1080, ISBN 0002-8614

Marzanski, M. (2000). Would You Like to Know What is Wrong with You? On Telling the Truth to Patients with Dementia. Journal of Medical Ethics, Vol.26, No.2, (April 1994), pp. 108-113, ISSN 0306-6800

Mayeux, R., Denaro, J., Hemenegildo, N., Marder, K., Tang, M.-X., Cote, L.J. \& Stern, Y. (1992). A population-Based Investigation of Parkinsons-Disease with and without Dementia - Relationship to Age and Gender. Archives of Neurology, Vol. 49, No.5, (May 1992), pp. 492-497, ISSN 0003-9942

McGrath, P. (1998). Autonomy, Discourse, and Power: a Postmodern Reflection on Principalism and Bioethics. Journal of Medicine and Philosophy, Vol.23, No.5, (August 1998), pp. 516-532, ISSN 0360-5310

Meisel, A., Kuczewski, M. (1996). Legal and Ethical Miths About Informed Consent. Archives of Internal Medicine, Vol.156, No.22, (December 1996), pp. 2521-2526, ISSN 0003-9926

Mendez, M.F., Cherrier, M., Perryman, K.M., Pachana, N., Miller, B.L. \& Cummings, J.L. (1996). Frontotemporal Dementia Versus Alzheimer's Disease: Differencial Cognitive Features. Neurology, Vol. 47, No.5, (November 1996), pp. 1189-1194, ISSN 0028-3878

Mental Capacity Act (2005). In: U.K. Legislation, 15.08.2011, Available from: www.opsi.gov.uk/acts/acts20050009.htm

Moroney, J.T., Bagiella, E., Desmond, D.W., Hachinski, V.C., Mölsä, P.K., Gustafson, L., Brun, A., Fischer, P., Erkinjuntti, T., Rosen, W., Paik, M.C. \& Tatemichi, T.K. (1997). Meta-analysis of the Hachinski Ischemic Score in Pathologically verified dementias. Neurology, Vol.49, No.4, (October 1997), pp. 1096-1105, ISSN 0028-3878 
Moye, J. \& Marson, D.C. (2007). Assessment of Decision-Making Capacity in Older Adults: An Emerging Area of Practice and Research. The Journals of Gerontology. Series B, Psychological Sciences and Social Sciences, Vol.62B, No.1, (May 2007), pp. 3-11, ISSN 1079-5014

Parsons, C., Hughes, C.M., Passmore, P. \& Lapane K.L. (2010). Withholding, Discontinuing and Withdrawing Medications in Dementia Patients at End of Life. Drugs Aging, Vol.27, No.6, (June, 2010), pp. 435-449, ISSN 1170-229X

Peterson, G. \& Wallin, A. (2003). Alzheimer's disease Ethics - Informed Consent and Related Issues in Clinical Trials: Results of a Survey Among the Members of the Research Ethics Committees in Sweden. International Psychogeriatrics, Vol.15, No.2 (June 2003), pp. 157-170, ISSN 1041-6102

Pinto, V.F. (1991). Between Life and Death, a Reason for Hope (an Ethical Assessment of Euthanasia, Dysthanasia and Orthothanasia). Servir, Vol.39, No.1, (JanuaryFebruary 1991), pp. 8-22, ISSN 0871-2379

Pioltini, A.B.M., Mendes-Chiloff, C.L., Schelp, A.O. \& Marcolino, E.S. (2010). Distinct Attitudes of Professionals from Different Medical Specialties Toward Autonomy and Legal Instruments in the Assessment of Patients with Alzheimer's Disease. Dementia \& Neuropsychologia, Vol.4, No.2, (June 2010), pp.104-108, ISSN 1980-5764

Prince, M., Livingston, G. \& Katona, C. (2007). Mental Health Care for the Elderly in LowIncome Countries: a Health Systems Approach. World Psychiatry, Vol.6, No.1, (February 2007), pp. 5-13, ISSN 1723-8617

Rendtorff, J.D. (2010). The Limitations and Accomplishments of Autonomy as a Basic Principle in Bioethics and Biolaw. In: Autonomy and Human Rights in Health Care, D.N. Weisstub \& G.D. Pintos (Eds), 75-76, Springer, ISBN 978.90.481.7453.9, The Netherlands.

Regnard, C., Leslie, P., Crawford, H., Matthews, D. \& Gibson, L. (2010). Gastrostomies in Dementia: Bad Practice or Bad Evidence? Age and Ageing, Vol.39, No.3, (May 2010), pp. 282-284, ISSN 0002-0729

Richter, J., Eisemann, M. \& Zgonnikova E. (2001). Doctor's Authoritarianism in End-of-Life Treatment Decision's. A comparison between Russia, Sweden and Germany. Journal of Medical Ethics, Vol.27, No.3, (June 2001), pp. 186-191, ISSN 0306-6800

Rohde, K., Peskind, E.R. \& Raskind, M.A. (1995). Suicide in Two Patients with Alzheimer's Disease. Journal of the American Geriatrics Society, Vol.43, No.2, (February 1995), pp. 187-189, ISSN 0002-8614

Roth, L.H., Meisel, A. \& Lidz, C.W. (1977). Tests of Competency to Consent to Treatment. The American Journal of Psychiatry, Vol.134, No.3, (March 1977), pp. 279-284, ISSN 0002-953X

Schelp, A.O., Nieri, A.B., Hamamoto Filho, P.D., Bales, A.M. \& Mendes-Chiloff, C.L. (2008). Public Awareness of Dementia. Dementia \& Neuropsychologia, Vol.2, No.3, (September 2008), pp. 192-196, ISSN 1980-5764

Schneiderman, J.L., Kaplan, R.M., Pearlman, R.A. \& Teetzel, H. (1993). Do Physician’s Own Preferences for Life-Sustaining Treatment Influence their Perceptions of Patient's Preferences? The Journal of Clinical Ethics, Vol.4, No.1, (Spring 1993), pp. 28-33, ISSN 1046-7890

Seckler, A.B., Meier, D.E., Mulvihill, M. \& Paris, B.E. (1991). Substituted Judment: How Accurate are Proxy Predictions? Annals of Internal Medicine, Vol.115, No.2, (July 1991), pp. 92-98, ISSN 0003-4819 
Silberfeld, M., Gundstein-Amadom, R., Stephens, D. \& Deber, R. (1996). Family and Physician's Views of Surrogate Decisions-Making: the Roles and How to Choose. International Psychogeriatrics, Vol.8, No.4, (Winter 1996), pp. 589-596, ISSN 1041-6102

Sittisombutt, S., Maxwell, C., Love, E.J. \& Sitthi-Amorin, C. (2009). Physician's Attitudes and Practices Regarding Advanced End-of-Life Care Planning for Terminally ill Patients at Chiang Mai University Hospital, Thailand. Nursing and Health Science, Vol.1, No.1, (March 2009), pp. 23-28, ISSN 1441-0745

Stiles, P.G. \& Petrila, J. (2011). Research and Confidentiality: Legal Issues and Risk Management Strategies. Psychology, Public Policy, and Law, Vol.17, No.3, (August 2011), pp. 333-356, ISSN 1076-8971

Strong, C. (1993). Patients Should not Always Come First in Treatment Decisions. The Journal of Clinical Ethics, Vol.4, No.1, (Spring 1993), pp. 63-65, ISSN 1046-7890

Teno, J.M., Clarridge, B.R., Casey, V., Welch, L.C., Wetle, T., Shield, R. \& Mor V. (2004). Family Perspectives on End-of-life Care at the Last Place of Care. The Journal of the American Medical Association, Vol.291, No.1, (January 2004), pp. 88-93, ISSN 00987484

U.S. Congress. (1994). Defensive Medicine and Medical Malpractice, OTA-H-602. Office of Technology Assessment, Washington, DC. , (July 1994), U.S. Government Printing Office.

Wendler, D. \& Rid, A. (2011). Systematic Review: the Effect on Surrogates of Making Treatment Decisions for Others. Annals of Internal Medicine, Vol.154, No.5, (March 2011), pp. 336-346, ISSN 0003-4819

White, D.B., Malvar, G., Karr, J., Lo, B. \& Curtis, J.R. (2010). Expanding the Paradigm of the Physician's Role in Surrogate Decision-Making: an Empirically Derived Framework*. Critical Care Medicine, Vol.38, No.3, (March 2010), pp. 743-750, ISSN 0090-3493

Whitney, S.N. \& McCullough, L.B. (2007). Physician's Silent Decision: Because Patient Autonomy Does Not Always Come First. The American Journal of Bioethics, Vol.7, No.7, (July 2007), pp. 33-38, ISSN 1526-5161

Widera, E., Steenpass, V., Marson, D. \& Sudore, R. (2011). Finances in the Older Patient With Cognitive Impairment "He Didn't Want Me to Take Over". The Journal of the American Medical Association, Vol.305, No.7, (February 2011), pp. 698-706, ISSN 0098-7484

Wild, K. \& Cotrell, V. (2003). Identifying Driving Impairment in Alzheimer's Disease: a Comparison of Self and Observer Reports Versus Driving Evaluation. Alzheimer's Disease and Associated Disorders, Vol.17, No.1, (January- march 2003), pp. 27-34, ISSN 0893-0341

World Health Organization (2011). Health Topics: Life Expectancy, In: World Health Organization,20.08.2011,Available from www.who.int/topics/life_expectancy/en/

Yaffe, M.J., Orzeck, P. \& Barylak, L. (2008). Family Physician's Perspectives on Care of Dementia Patients and Family Caregivers. Canadian Family Physician, Vol.54, No.7, (July 2008), pp. 1008-1015, ISSN 0008-350X

Yarborough, M. (2002). Adults Are Not Big Children: Examining Surrogate Consent to Research Using Adults With Dementia. Cambridge Quarterly of Healthcare Ethics, Vol.11, No.2, (Spring 2002), pp. 160-168, ISSN 0963-1801 


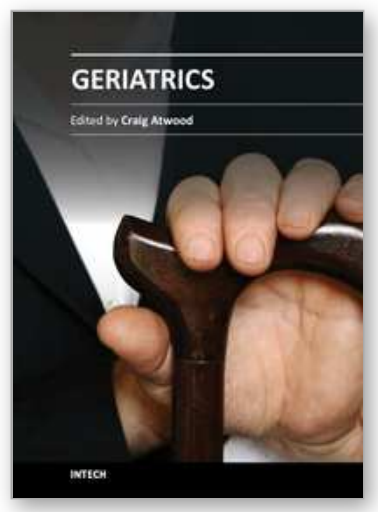

\author{
Geriatrics \\ Edited by Prof. Craig Atwood
}

ISBN 978-953-51-0080-5

Hard cover, 246 pages

Publisher InTech

Published online 24, February, 2012

Published in print edition February, 2012

With the baby boomer generation reaching 65 years of age, attention in the medical field is turning to how best to meet the needs of this rapidly approaching, large population of geriatric individuals. Geriatric healthcare by nature is multi-dimensional, involving medical, educational, social, cultural, religious and economic factors. The chapters in this book illustrate the complex interplay of these factors in the development, management and treatment of geriatric patients, and begin by examining sarcopenia, cognitive decline and dysphagia as important factors involved in frailty syndrome. This is followed by strategies to increase healthspan and lifespan, such as exercise, nutrition and immunization, as well as how physical, psychological and sociocultural changes impact learning in the elderly. The final chapters of the book examine end of life issues for geriatric patients, including effective advocacy by patients and families for responsive care, attitudes toward autonomy and legal instruments, and the cost effectiveness of new health care technologies and services.

\title{
How to reference
}

In order to correctly reference this scholarly work, feel free to copy and paste the following:

Arthur Oscar Schelp (2012). End of Life Care: Attitudes Toward Autonomy and Legal Instruments, Geriatrics, Prof. Craig Atwood (Ed.), ISBN: 978-953-51-0080-5, InTech, Available from:

http://www.intechopen.com/books/geriatrics/end-of-life-care-attitudes-toward-autonomy-and-legal-instruments

\section{INTECH}

open science | open minds

\author{
InTech Europe \\ University Campus STeP Ri \\ Slavka Krautzeka 83/A \\ 51000 Rijeka, Croatia \\ Phone: +385 (51) 770447 \\ Fax: +385 (51) 686166 \\ www.intechopen.com
}

\author{
InTech China \\ Unit 405, Office Block, Hotel Equatorial Shanghai \\ No.65, Yan An Road (West), Shanghai, 200040, China \\ 中国上海市延安西路65号上海国际贵都大饭店办公楼 405 单元 \\ Phone: +86-21-62489820 \\ Fax: +86-21-62489821
}


(C) 2012 The Author(s). Licensee IntechOpen. This is an open access article distributed under the terms of the Creative Commons Attribution 3.0 License, which permits unrestricted use, distribution, and reproduction in any medium, provided the original work is properly cited. 